\title{
Relevansi Makna Empat Drama Anak-anak Berbasis Cerita Dongeng Nusantara Bagi Generasi Masa Kini
}

\author{
Nur Sahid $^{1 *}$, Junaedi \\ ${ }^{1}$ Jurusan Seni Teater, Fak. Seni Pertunjukan, ISI Yogyakarta \\ ${ }^{2}$ Jurusan Seni Pedalangan, Fak. Seni Pertunjukan, ISI Yogyakarta \\ $\underline{\text { nur.isijogja@yahoo.co.id }}^{1 *}$
}

Penelitian ini bertujuan untuk menggali makna tanda-tanda yang terdapat dalam empat drama ",Asal-usul Gunung Merapi ', 'Putri Si Anak Durhaka', "Candra Kirana', dan 'Malapetaka Sang Raksasa'. Teori pendekatan yang dipakai untuk menganalisis adalah semiotika versi Ferdinand De Saussure yang dibantu dengan analisis makna tanda dari Rolanf Barthes. Metode yang dipakai dalam penelitian adalah purposive sampling, sedangkan analisis data menggunakan metode semiotika. Hasil penelitian ini menunjukkan bahwa dongeng Nusantara dapat digubah ke dalam genere seni drama, khususnya drama anak-anak. Dengan digubah ke dalam drama akan memiliki peluang audiens yang lebih luas. Keempat dongeng mengandung makna denotatiie dan konotatif. Makna denotative terkait dengan kesrkahan dan egoisme, ketidakadilan, pegergeseran sistem nilai masyarakat, dan kegigihan dalam mengejar cita-cita, kebaikan melawan kejahatan. Makna konotatif terkait relevansinya semua makna konotatif dengan kondisi sosial historis masyarakat Indonesia sekarang. Maknamakna keempat dongeng cukup relevan untuk pendidikan moral generasi sekrang, sehinga sudah selayaknya diperkenalkan kepada generasi masa kini.

Kara kunci: dongeng, semiotika, makna denotative, makna konotatif, pendidikan moral

\section{The Relevance Of The Meaning Of Four Children's Dramas Based On Nusantara Dongeng Stories For The Current Generation}

This study aims to explore the meaning of the signs contained in the four plays ", The Origins of Mount Merapi ", "Putri Si Anak Durhaka", "Candra Kirana", and "Malapetaka Sang Giant". The theoretical approach used to analyze is Ferdinand De Saussure's version of semiotics assisted by analysis of the meaning of signs from Roland Barthes. The method used in this research is purposive sampling, while the data analysis uses the semiotic method. The results of this study indicate that the fairy tales of the Archipelago can be transformed into the genre of drama arts, especially children's dramas. By being made into a drama, it will have a wider audience opportunity. The four fairy tales contain denotative and connotative meanings. Denotative meanings are related to greed and egoism, injustice, shifts in the value system of society, and persistence in pursuing ideals, good against evil. The connotative meaning is related to the relevance of all connotative meanings to the historical social conditions of Indonesian society today. The meanings of the four fairy tales are quite relevant for the moral education of the current generation, so they should be introduced to the present generation.

Keywords: fairy tales, semiotics, denotative meaning, connotative meaning, moral education

Received: August 23, 2021; Accepted February 2, 2022; Published February 7, 2022 https://doi.org/10.31091/mudra.v37i1.1685 (C) 2021 The Author(s). Published by Pusat Penerbitan LP2MPP Institut Seni Indonesia Denpasar. This is an open-access article under the CC BY-NC-SA license 


\section{PENDAHULUAN}

Dongeng atau cerita rakyat muncul dan hidup di berbagai wilayah di Indonesia. Misalnya, cerita "'Andhé- Andhé Lumut", 'Jaka Tarup", 'Timun Emas" (Jawa Tengah), "Sangkuriang" (Jawa Barat), "Calon Arang'" (Bali, Malin Kundang (Sumatera), "Dumadining Gunung Merapi", (Daerah Istimewa Yogyakarta), 'Batu Menangis"' (Kalimantan Barat), 'Keong Mas" (Jawa Timur) dan sebagainya. Beberapa karya di atas hanyalah sebagain kecil dari khazanah cerita rakyat di tanah air. Hal ini karena koleksi cerita rakyat di setiap daerah atau etnis cukup banyak. Sekedar contoh, Provinsi Daerah Istimewa Yogyakarta memiliki 63 cerita rakyat (Nursinggih, 20017). Jumlah tersebut masih bersifat sementara, sebab semua dongeng belum dibukukan. Begitu pula di daerah yang lain, hampir pasti memiliki cerita rakyat yang cukup banyak.

Kandungan nilai-nilai edukasi cikup signifikan dalam cerita rakyat Nusantara. Tidak mengherankan apabila ada sejumlah seniman yang menggubah dongeng-dongeng itu dalam bentuk drama, cerita fiksi, film animasi, film layar lebar dsb. Tujuan para kreator cukup jelas, yakni ingin memasyarakatkan nilai-nilai pendidikan dongeng Nusantara lewat genre seni lain. Dramawan Nanang Arizona asal Yogyakarta telah mengadaptasi beberapa dongeng menjadi naskah drama. Misalnya, ia telah mengadaptasi dongeng "Batu Menangis" menjadi "'Putri Si Anak Durhaka" (2014), 'Keong Mas", menjadi "Candra Kirana" (2016), dan "Timun Emas" menjadi "Malapetaka Sang Raksasa" (2016). 'Dumadining Gunung Merapi' menjadi "'Asal-usul Gunung Merapi ' (2018)'.

Secara tematik amanat yang dikandung dalam drama-drama Nanang Arizona sama dengan cerita aslinya. Yang berbeda adalah jumlah tokoh cerita yang lebih banyak. Hal ini membawa konskuensi plot cerita menjadi lebih panjang. Bila dongengdongeng itu lebih dikonsumsikan sebagai bacaan, sedangkan drama-drama hasil gubahan untuk naskah pertunjukan drama atau teater anak-anak. Dengan demikian, anak-anak memiliki peluang untuk dapat bermain teater. Kajian ini tidak bermaksud membahas proses kreatif Arizona dalam penciptaan drama-drama yang bersumber dari cerita rakyat Nusantara. Namun difokuskan relevansi makna drama-drama itu bagi generasi sekarang.

Perlu diketahui bahwa sekalipun berasal dari budaya local, berbagai dongeng Nusantara dan dramadrama tersebut menarik untuk disimak. Hal ini karena karya-karya itu merupakan salah satu ekspresi seni budaya yang memiliki arti strategis bagi pembinaan mental bangsa. Dalam cerita rakyat terkandung pesan moral atau amanat yang cukup signifikan seperti ajaran tentang relijiusitas, kejujuran, hormat terhadap yang lebih dan orang tua, kemanusiaan, kebersamaan, toleransi dsb. Selain itu, dongeng juga bermanfaat untuk pendidikan karakter anak-anak sekolah. Hal ini dapat dilakukan dengan memberikan sebuah cerita yang mengandung pesan-pesan moral (Fitroh dan Sari, 2015). Tentu saja tidak terkecuali dengan dramadrama hasil gubahan Nanang Arizona

Misalnya, dalam drama 'Asal-usul Gunung Merapi" tokoh Narada, Batara Guru dan para dewa lainnya memiliki sikap kemanusiaan yang tinggi. Mereka membantu penghuni Pulau Jawa dari resiko tanah kelahiran mereka yang akan tenggelam. Caranya adalah dengan memindahkan gunung Jamur Dipa dari laut selatan ke tengah-tengah Pulau Jawa. Dalam kisah "Putri Si Anak Durhaka" diajarkan tentang bahaya apabila tidak menghormati orang tua. Sebab doa orang tua yang teraniaya akan dikabulkan Tuhan. Terbukti dalam kisah ini Putri menjilma menjadi wanita yang bisu dan hanya bisa menangis akibat setelah seian lama menyia-nyiakan orang tuanya. Dalam "Candra Kirana" diajarkan tentang kejujuran dan penghormatan kepada saudara yang lebih tua. Tokoh Galuh memfitnah kakak perempuannya bernama Candra Kirana dengan tuduhan mengambil kalung emas. Hal itu menyebabkan ia diusir dari istana. Akhirnya fitnah Galuh diketahui sang ayah Raja Daha, sehingga ia diusir dari istana. Sementara itu, 'Malapeta Sang Raksasa" menyampaikan nilai-nilai pendidikan tentang arti penting bekerja keras untuk mencapai cita-cita luhur.

Drama ",Asal-usul Gunung Merapi ', "Putri Si Anak Durhaka", "Candra Kirana", dan 'Malapetaka Sang Raksasa" mengandung unsurunsur simbol atau bersifat simbolik (tanda-tanda). Tokoh-tokoh dalam 'Asal-usul Gunung Merapi'" adalah simbolisasi dari pertentangan perilaku manusia mementingkan diri sendiri (serakah dan egois) dan para Dewa yang arif bijaksana. Tokohtokoh dalam "Malapetaka Sang Raksasa" mencerminkan simbolisasi dari perlawanan manusia yang baik melawan manusia serakah. Tokoh-tokoh dalam 'Putri Si Anak Durhaka"' adalah simbolisasi manusia-manusia yang tidak mematuhi ajaran moral dan agama dan baik hati. Tokoh-tokoh dalam "Candra Kirana" merupakan simbolisasi dari manusi-manusia yang tidak dapat bersikap adil, serakah, dan baik hati.

Ajaran moral yang terkandung dalam drama-drama tersebut menarik untuk dikaji. Hal ini karena nilai- 
nilai ajaran moral tersebut tetap memiliki nilai relevansi bagi generasi sekarang dari usia dini hingga remaja, sekalipun usia cerita rakyat sudah ratusan tahun. Nilai relevansi yang dimaksud khususnya terkait dengan masalah pembinaan mental atau pendidikan budi pekerti yang penting artinya bagi penyeimbang kehidupan material manusia (Choriyah, 2020). Pembinaan mental berkaitan dengan usaha peningkatan kesanggupan rokhaniah untuk menghayat semua segi kehidupan dan tata nilai yang berlaku dalam masyarakat. Tujuannya adalah untuk mencapai kebahagiaan hidup lahir dan batin.

Keempat drama karya Arizona banyak mengandung unsur simbol atau tanda-tanda (sign). Dalam tandatanda tersebut terimplisisr makna-makna simbolik baik dalam kaitan hubungan manusia dengan Sang Pencipta, manusia dengan manusia, manusia dengan makhluk lain, dan manusia dengan alam sekitarnya. Untuk itu, penulis tetarik untuk mengkaji karya tersebut dengan pendekatan semiotika. Teori semiotika dianggap relevan untuk mengkaji keempat drama, karena muatan tanda-tanda yang cukup signifikan di dalamnya.

Berangkat dari uraian di atas dapat diambil rumusan permasalahan sebagai berikut, yakni keepat drama menjadi sample penelitian mengandung tanda-tanda yang maknanya yang relevan bagi generasi masa kini, termasuk anak-anak usia dini dan remaja, sehingga perlu dikaji dengan pendekatan semiotika teater. Tujuan dari penelitian ini adalah untuk mengkaji makna-makna tanda-tanda yang terkandung dalam drama ",Asal-usul Gunung Merapi ", "Putri Si Anak Durhaka", "Candra Kirana”, "Malapetaka Sang Raksasa".

\section{METODE PENELITIAN}

Sesuai tujuan penelitian ini maka metode penelitian yang relevan adalah metode kualitatif (Mitchell Jr, et all, 2020) dan semiotika. Pemilihan keempat drama karya Arizona sebagai sampel berdasarkan purposive sampling, yakni teknik pemilihan sampel disesuaikan dengan masalah, kebutuhan, dan kemantaban peneliti dalam memperoleh data (Sugiono, 2015: 76: 23, Cf. Setiawan, 2020). Dalam hal ini, keempat dongeng Nusantara yang menjadi sumber inspirasi penciptaan keempat drama karya Nanang Arizana juga akan dibaca sebagai data pembanding. Data-data tentang dongeng Nusantara diperoleh lewat buku dan internet, yakni "Dumadine Gunung Merapi' (Ernawati, 2017), 'Timun Emas", (https://dongengceritarakyat.com/cerita-legendatimun-mas-dongeng/), "Keong Mas" (https://histori.id/legenda-keong-mas/), dan 'Batu Menangis",

(https://dongengceritarakyat.com/cerita-rakyat-

legenda-batu-menangis/). Dongeng merupakan cerita lisan bersifat anonim yang diwariskan dari generasi ke generasi. Dengan demikian cerita dengan judul yang sama akan muncul dalam berbagai versi atau tergantung siapa yang menuturkan. Namun demikian secara substansial plot cerita dari berbagai versi tersebut sama.

Analisis data menggunakan metode semiotika. Secara umum, cara kerja metode semiotika mencakup empat langkah sebagai berikut (Pradopo, 2000: 7). Pertama, yang dianalis adalah jenis-jenis tanda yang penting dan berhubungan dengan konteks tanda-tanda itu. Analisis data dimulai dengan mencatat tanda-tanda yang bermakna yang terdapat dalam ketiga dongeng dan video. Tandatanda yang bermakna dapat muncul pada narasi penceritaan, dialog antar tokoh, dan latar. Kedua, berusaha menyendirikan unsur-unsur yang dipergunakan dalam sistem itu, misalnya perwatakan tokoh, peristiwa, latar dan menentukan kontras-kontras di antara unsur-unsur itu. Ketiga, karya dongeng yang dikaji memiliki konvensikonvensi, sehingga tanda-tanda yang ada memiliki makna. Keempat, tanda-tanda yang diburu adalah tanda-tanda yang antara satu dengan yang lain berhubungan erat.

\section{LANDASAN TEORI}

Semiotika merupakan ilmu tentang tanda dan sistem tanda. Keir Elam (1991: 1) menyebut semiotika sebagai ilmu yang khusu memproduksi makna dalam masyarakat. . Dengan pengertian di atas dapat dikatakan bahwa objek semiotika adalah kode-kode dan sistem-sistem tanda yang ada di masyarakat (Sahid, 2019: 2). Semiotikawan klasik Rusia Jurij Lotman (Burger, 2014) mengatakan bahwa penandaan dalam semiotika menjadi media untuk membuka rahasia yang ditemukan dalam budaya dan alam semesta'. Lebih jauh dikatakan Lotman bahwa analisis semiotika dapat mengungkapkan halhal menarik tentang budaya dan masyarakat, termasuk teks sastra dan seni. Dalam wacana drama, semiotika memungkinkan investigasi teks drama secara struktural, sedangkan dalam wacana teater, semiotika memberikan suatu metabahasa yang dapat dipakai untuk menganalisis bahasa-bahasa gambar, fisik, dan aural (auditif) dalam teater Aston \& Savona (1999: 10). Dalam penelitian ini akan difokuskan pada empat karya drama karya Nanang Arizona bukan sebagai pertunjukan teater, tetapi karya drama yang dilihat sebagai salah satu genre sastra (Wellek dan Warren, 1989: 300). 
Pendekatan semiotika meliputi analisis teks naratif (fiksi, dongeng, drama dsb) sebagai sebuah penggunaan bahasa yang berdasar pada konvensikonvensi tambahan meliputi ciri-ciri yang memberikan makna pada bermacam-macam modus wacana (Preminger dkk., dalam Wibowo dan Ali, 2017)). Dengan melihat variasi-variasi dalam struktur karya fiksi atau hubungan antar unsurnya akan dihasilkan bermacam-macam makna. Tokoh semiotika Ferdinand de Saussure mengatakan bahwa tanda dalam semiotika memiliki dua aspek, yakni penanda (signifier) yang merupakan konsep atau bentuk tanda yang menandai petanda (signified) yang merupakan maknanya (Binder, 2020). Berdasarkan hubungan antara penanda dengan petandanya, maka tanda dibedakan menjadi tiga macam, yakni ikon, indeks, dan simbol. Charles Sander Pierce mengatakan ikon adalah tanda yang penanda dengan petandanya memiliki hubungan kemiripan; indeks adalah tanda yang penanda dan petandanya memiliki hubangan kausalitas; sedangkan tanda yang penanda dan petandanya ditandai hubungan yang bersifat arbitrair disebut simbol (Noth, 1990: 45). Akan tetapi dalam kajian ini model penandaan Saussure yang dipakai bukan dari Pierce, sebab dianggap lebih relevan dengan objek yang dikaji.

Berbagai fakta yang ada menunjukkan bahwa sebagian besar tanda bahasa berupa simbol. Dalam hubungannya dengan karya sastra, Preminger dkk. (Pradopo, 2013) mengatakan bahwa bahasa merupakan sistem tanda tingkat pertama (first order semiotics), sedangkan sastra merupakan sistem tanda tingkat kedua (second order semiotics). Arti bahasa adalah arti (meaning), sedangkan arti sastra adalah arti dari arti (meaning of meaning) atau makna (significance). Substansi semiotika dalam analisis teks naratif, termasuk dongeng, adalah untuk memberi makna karya sastra sebab karya teks sastra merupakan sistem tanda mempunyai makna. Rolland Barthes menyebut terdapat dua lapis makna dalam sebuah karya, yakni makna denotatif dan konotatif (Al-Shraideh1 dan El-Sharif, 2019; Nur Sahid, 2016). Makna denotasi merupakan arti sebuah kata sebagaimana yang biasa dipergunakan dalam kehidupan sehari-hari. Sedangkan makna konotatif merupakan makna tataran kedua, ketiga dan seterusnya dari sebuah kata atau sering disebut sebagai makna kiasan. Riffaterre mengemukakan bahwa pemaknaan karya sastra, termasuk dongeng, sebagai sistem tanda-tanda dengan istilah memproduksi makna tanda-tanda (1982: 23). Karya sastra sebagai struktur tanda merupakan artefak yang belum mempunyai makna sebelum diberi makna oleh pembaca (Vodicka dalam Teeuw, 1984: 191).

\section{HASIL PENELITIAN}

Dongeng sebagai cerita rakyat termasuk karya sastra bergenre fiksi atau cerita rekaan. Termasuk dalam genre fiksi adalah novel, roman, dan cerpen. Cerita fiksi selalu mengandung unsur-unsur cerita seperti tema, penokohan, plot, latar, dan alat-alat penceritaan lain semacam gaya bahasa, sudut pandang dsb (Nur Sahid, 2017). Dalam konteks ini, kajian difokuskan pada unsur penokohan. Ini karena tanda-tanda semiotika yang perlu diberi makna banyak ditemukan dalam penpkohan. Pada unsur penokohan tersurat tanda-tanda yang cukup signifikan utama yang terkait dengan perwatakan seperti sikap hidup dan kebiasaan para tokoh cerita. Secara kongkrit tanda-tanda yang dimaksud adalah simbolisasi watak kesrakahan dan egoisme, ketidakadilan, pergeseran sistem nilai, dan mengejar impian.

\section{Simbolisasi Makna Kesrakahan dan Egoisme}

\section{Makna Denotatif}

Dalam dongeng "'Dumadine Gunung Merapi" tokoh tokoh Empu Permadi sudah diminta para Dewa seperti Batara Guru, Narada, Panyarikan, Sambu dan Bayu agar menghentikan kegiatan pande besi membuat keris dll. Mpu Rama dan Mpu Permadi diminta pindah ke lokasi lain. Tempat pande besi itu akan dipakai lokasi pemindahan Gunung Jamur Dipa dari Laut Selatan. Tujuan pemindahan itu adalah agar tanah Jawa tidak miring dan tenggelam, sehingga seluruh makhluk dapat diselamatkan. Empu Permadi menolak permintaan para Dewa dari kahyangan.

\section{Dewa Narada:}

Saya disuruh Batara Guru untuk menyampaikan kabar ke Mpu Rama dkk. Gunung Jamur Dipa akan dipindah ke sini.

Mpu Rama:

Apa tujuannya? Saya sudah berpuluh tahun tinggal di sini.

Dewa Sambu:

Tanah Jawa yang kalian tempati sudah miring. Lama-lama bisa tenggelam ke laut bila tidak ditindih gunung.

Dewa Panyarikan:

Kasihan manusia yang tinggal di Tanah Jawa bila sampai tenggelam.

Mpu Parmadi:

Saya tidak setuju dengan rencana itu. Terkecuali nanti setelah seтua garapan keris sudah selesai.

Dewa Narada:

Lha itu memerlukan waktu berapa hari? 
Mpu Rama dan Parmadi:

Wah kami tidak tahu Dewa. Karena pesanan keris cukup banyak.

Karto:

Pak Rama dan Parmadi sebaiknya patuhi permintaan para Dewa. Ini kan demi keselamatan umat manusia di Tanah Jawa (SALAH SEORANG PEMBANTU RAMA DAN PARMADI MENCOBA MEMBERI NASEHAT).

Mpu Rama:

Tidak Karto. Saya tidak setuju dengan nasehatmu. Sebab kalau keris-keris tidak saya selesaikan lebih dalu akan menyebabkan bencana di tempat ini (Arizona, 2018: 6-7)

Sikap Mpu Rama dan Mpu Permadi yang menolak permintaan para dewa dalam perspektif semiotika Saussure merupakan penanda, sedangkan maknanya (petanda) secara denotative mengacu manusia yang berwatak serakah dan egois. Mereka tampak memntingkan keuntungannya sendiri. Mereka tidak mau mengalah demi kepentingan umat manusia yang lebih besar.

Dalam dongeng ' Keong Mas' tokoh Dewi Galuh meminta ayahanda agar dirinya yang dijodohkan dengan Inu Kertapati. Ia menganggap dirinya lebih cocok. Padahal yang dijodohkan Inu adalah kakaknya Candra Kirana, bukan dirinya. Raden Inu Kertapati sangat tampan, sehingga ia iri dan dengki terhadap Candra Kirana.

\section{Raden Kertamarta:}

Baiklah. Karena Permaisuri dan Candra Kirana sudah setuju. Saya pun menerima lamaran Raden Inu Kertapati. Begitu keputusannya Raden Inu Kertapati.

Inu Kertapati:

Terimakasih Tuan Raja, Ibu Permasuri, dan Candra Kirana.

Dewi Galuh:

(TIBA-TIBA DEWI GALUH MENDEKATI AYAHANNDA)

Ayahanda. Raden Inu Kertapati kenapa tidak dijodohkan dengan saya. Kan saya lebih cantik.

Raden Kertamarta:

Dewi Galuh. Kamu lebih muda dari kakakmu. Jadi menikahnya harus urut dari yang tua lebih dulu.

Dewi Galuh:

Tidak mau Romo. Pokoknya harus saya yang menjadi istri Kangmas Inu Kertapati (MENANGIS

DAN AGAK MEMAKSA)

Raden Kertamarta:

Kamu lihat, ini di pertemuan agung. Ada tamu terhormat dari Kahuripan. Apa kamu tidak malu berbuat seperti itu?

Dewi Galuh:
Romo kenapa Kak Candra selalu lebih beruntung daripada saya (SAMBIL MENANGIS) (Arizona, 2016: 4).

Secara denotative sifat Dewi Galuh yang berkeinginan kuat memiliki Inu Kertapati yang telah dijodohkan dengan Candra Kirana merupakan penanda bahwa ia manusia yang serakah dan egois (petanda). Ia ingin menerjang aturan dengan menghalalkan berbagai cara agar dapat memiliki Inu Kertapati.

Tokoh Raksasa dalam "Timun Emas" berkali-kali meminta Mbok Yem agar menyerahkan Timus Emas kepadanya. Sebab dalam perjanjian setelah Timun Emas besar harus dierahkan ke Raksasa untuk dimangsa (dimakan). Tugas Mbok Yem hanya membesarkan Timun Emas. Mbok Yem menolak permintaan Raksasa. Ia sangat menyayangi Timun Emas. Ia heran mengapa Raksasa suka makan manusia.

"Cepat serahkan anakmu atau ku hancurkan rumah beserta dirimu! Aku sudah sangat lapar!” teriak raksasa.

" Maaf, Tua raksasa. Anakku sudah berjalan ke hutan. Kembalilah engkau ke hutan tempat tinggalmu. Timun Mas sudah berada di sana." Kata Mbok berbohong.

Pada saat itu. Timun Mas sudah keluar rumah melalui pintu belakang. Ia membawa semua benda yang di berikan oleh kakek sakti dari gunung itu. Ketika akan kembali ke hutan, si raksasa melihat Timun Mas berlari dari belakang rumah. Di kejarnya Timun Mas.

(https://dongengceritarakyat.com/cerita-legendatimun-mas-dongeng/ )

Sikap Raksasa yang merebut Timun Emas dari Mbok Yem untuk dimangsa (penanda) bermakna bahwa secara denotaif ia termasuk makhluk yang serakah dan egois (petanda). Ia tidak merasa kasihan kepada Mbok Yem yang tidak memiliki anak. Beruntung bahwa Timun Emas akhirnya berhasil membunuh Raksasa. Itu semua akibat ia diberi sejata kesaktian oleh seorang Resi.

\section{Makna Konotatif}

Kesrakahan yang dilakukan Mpu Rama, Mpu Parmadi, Dewi Galuh, dan Raksasa sebagaimana dipaparkan di atas mengacu pada makna denotative atau makna tahap pertama. Barthes mengatakan bahwa dalam semiotika makna sebuah objek karya seni tidak hanya bersifat denotative, tetapi juga konotatif (Al-Shraideh1 dan El-Sharif, 2019). Makna konotatif merupakan makna tataran kedua 
dan seterusnya atau sering disebut dengan makna kiasan. Dalam konteks ini, makna sikap kesrakahan dan egoisme tokoh Mpu Rama, Mpu Permadi, Raksasa, dan Dewi Galuh (penanda) secara sosial historis mengacu kepada fugur-figur yang serakah dan egois di negeri ini (petanda). Figur atau manusia yang serakah dan egois bisa mengacu kepada pihakpihak yang sewenang-wenang saat memiliki kekuasaan politik dan uang seperti pemimpin, pejabat negara, wakil rakyat dll yang lebih mengutamakan kepentingan sendiri. Ketika seorang pejabat bertindak sewenang-wenang, ia akan bebas melakukan apa pun korupsi, kolusi, dan nepotisme (KKN). KKN yang diperjuangkan sejak era reformasi ternyata hingga saat ini belum sepenuhnya berhasil. Bahkan samapai hari ini korupsi terus merebak di berbagai sektor.

Ka'bah (2007) mengatakan bahwa orang-orang yang sering jadi panutan masyarakat seperti pejabat, DPR dll sering menyalahgunakan jabatan dengan melakukan korupsi uang rakyat. Apabila korupsi dibiarkan merajalela, maka akan melahirkan krisis kepercayaan, sikap putus asa, kehilangan kepemimpinan publik dan lain-lain. Sebagai pemimpin seharusnya mereka tidak serakah dengan mengumpulkan kekayaan untuk kepentingan pribadi dan kelompoknya. Tindakan demikian pada dasarnya merupakan bentuk egoisme yang jauh dari nilai-nilai keadilan sosial. Berbagai cara untuk memberantas korupsi telah dilakukan kalangan eksekutif, legislative, dan yudikatif lewat berbagai perundang-undangan. Berbagai aturan dan lembaga sudah ada seperti BPK, BPKP, Tim Anti Korupsi, Irjen, KPK, ICW dsb, namun korupsi tetap meruyakmerajalela (Mu'allifin, 2015). Paparan di atas merupakan salah satu makna konotatif dari sikap kesrakahan dan egoisme tokoh Mpu Rama, Mpu Permadi, Raksasa, dan Dewi Galuh.

\section{Simbolisasi Makna Ketidakadilan}

\section{Makna Denotatif}

Tokoh Raja Kartamarta dalam 'Keong Mas" dengan mudahnya membuang Candra Kirana ke sungai lantaran berubah berwajah jelek dan menjijikkan. Hal itu terjadi akibat Dewi Galuh meminta bantuan Nenek Sihir agar menyihirnya. Candra Kirana berubah menjadi keong mas setelah dibunga ke sungai. Beruntung ia diketemukan seorang Nenek yang baik hati, sehingga dipelihara dalam tempayan.

Penyihir:

Apakah kamu Candra Kirana?

Candra Kirana:

Betul Kek! Kok sudah tahu nama saya?

Penyihir:
Saya dimintai tolong Dewi Galuh agar menyihir kamu menjadi binatang menjijikkan. Sehingga Inu Kertapati tidak melihatmu lagi.

(PENYIHIR MENGUCAPKAN MANTRA-

MANTRA KEMUDIAN KEDUA TANGANNYA

MENGUSAP TUBUH CANDRA KIRANA.

SECEPAT KILAT CANDRA KIRANA BERUBAH

MENJADI KEONG MAS. PENYIHIR

MEMBUANG KEONG MAS DI SUNGAI )

(Arizona, 2017: 7).

Sebagai orang tua seharunya ia menerima apa pun kondisi wajah anaknya. Ia justru membela Galuh. Sikap Kertamarta yang lebih membela Galuh (penanda) bermakna ia telah berskap tidak adil (petanda).

\section{Makna Konotatif}

Ketidakadilan perilaku Kertamarta dalam menghadapi kedua memiliki makna konotatif yang mengacu kepada berbagai bentuk ketidakadilan selama ini terjadi di Indonesia (petanda). Sebagai contoh, ketidakadilan di bidang hokum pun terjadi di negeri ini. Kadang-kadang hukum saat berhadapan dengan pihak yang memiliki kekuasaan semacam kekuasaan politik, uang akan menjadi tidak berdaya (Amrunsyah, 2017). Sebaliknya, apabila berkaiatan dengan orang miski atau tidak memiliki kekuasaan hokum menjadi kuat dan tajam. Semua itu terjadi akibat hokum tidak dijalankan secara adil dan beradab.

Dalam bidang media pun menunjukkan ketidakadilan akibat munculnya konglomerasi media. Akibatnya pewartaan di media menjadi tidak adil, sebab banyak opini yang disampaikan menjurus kepada kepentingan kelompok tertentu. Sebagian media telah menjadi tangan panjang untuk kepentingan politik para pemiliknya (Pembayun, 2015). Malahan tidak sedikit media dengan terangterang menjual celahcelah titipan agenda setting bagi siapa saja yang siap membayar. Tentu saja masih banyak lagi ketidakadilan bidang lain seperti eknomi, politik, sosial dll yang dapat dipaparkan. Akan tetapi dengan 2 contoh di atas cukup sebagai argumentnasi tentang makna konotatif dari perilaku tidak adil tokoh Kertamarta.

\section{Simbolisasi Makna Pergeseran Sistem Nilai}

Tokoh Putri dalam 'Batu Menangis' dikisahkan sebagai gadis yang cantik. Suatu saat ia diajak ibunya belanja ke pasar. Setiap pemuda yang bertemua di jalan mengagumi kecantikannya. Sepanjang perjalanan, Putri selalu jalan di depan tidak mau bersama ibunya. Ia merasa malu ibunya yang dianggap buruk rupa dan miskin. Malahan ia tidak mau mengakui sebagai ibunya. 
Amir:

Nona, sejak tadi saya lihat kalian. Tapi jalannya berjauhan. Memangnya di belakang itu siapa?

Putri:

Saya tidak kenal orang tua yang jelek itu.

Fatimah:

Oh..jadi kamu tak mau mengakui aku ibumu? (FATIMAH MARAH SAMBIL MEMBENTAK PUTRI)

Putri:

Tidak. Kamu tak pantas jadi ibuku. Kamu miskin, jelek, dan cerewet. (SUARA PUTRI SANGAT KERAS SEHINGGA MEMBUAT FATIMAH SANGAT KAGET. SEKETIKA ITU JUGA FATIMAH DUDUK BERSIMPUH. IA MEMANJATKAN KEPADA ALLOH SWT).

Fatimah:

Astaghfirrullahal Adzim. Ya Alloh ampunkan dosa anakku yang telah durhaka ini. (MENANGIS DAN MENCUCURKAN AIR MATA. SEKETIKA ITU JUGA PUTRI TIDAK BISA BICARA. IA HANYA BISA NGOMONG A..U...A..U. PUTRI BISU).

Putri:

A..U..A...U (PUTRI MENANGIS MEMELUK IBUNYA. TAPI IA TIDAK BISA NGOMONG APAAPA LAGI ALIAS BISU).

Fatimah:

Anakku bisu? Ya Alloh ampunkan dosa-dosa anakku. Ya Alloh saya telah memaafkan semua kesalahannya (FATIMAH MENANGIS LAGI. SAMBIL BERDOA KEPADA ALLAH SWT)

(Arizona, 2014: 10).

Akibat sakit hati kemudian ibunya memohon kepada Tuhan agar Putri diberi hukuman. Tuhan mengabulkan doanya dan Putri berubah menjadi batu yang menangis. Ia menangis menyesali perbuatannya. Namun penyesalan itu sudah terlambat. Ia tidak dapat pulih kembali seperti semula. Putri berparas cantik, tetapi berwatak jahat. Perbuatan Putri yang tidak berbakti kepada ibunya (penanda) mengacu kepada makna bahwa ia tidak mengindahkan sopan santun dan rasa hormat kepada orang tuanya (petanda).

\section{Makna Konotatif}

Tidakan Putri yang sama sekali tidak menghormati ibunya (penanda) secara kononatif dapat mengacu kepada makna tentang telah terjadinya sistem nilai dalam masyarakat Indonesia (petanda). Sebagaimana diketahui bahwa modernisasi dalam bidang teknologi informasi saat ini telah cukup pesat. Lajunya arus informasi merupakan salah satu penyebab terjadinya pergeseran sistem nilai dalam masyarakat. Dalam hal ini, interaksi antara masyarakat dengan berbagai sistem nilai baru berupa pergaulan yang permisif, adegan kekerasan yang berlebihan, pola hidup sekuler dll. yang dibawa oleh tayangan-tayangan film asing (barat) di televisi, gadget, gambar-gambar penuh kekerasan, pornografi di internet telah menyebabkan masyarakat merasa mendapat tawaran nilai-nilai baru yang berbeda dengan sistem nilai lama yang berbasis dari nilai-nilai agama dan budaya yang selama ini menjadi miliknya. Kemajuan kehidupan teknologi dan ekonomi, telah menyebabkan sebagian warga masyarakat menjadi kaya dalam materi tetapi miskin dalam rohani (Yoga, 2018).

Yang kemudian banyak terjadi adalah adanya kecenderungan sebagian masyarakat kita yang justru larut dalam sistem nilai yang baru itu. Hal tersebut akan membawa dampak yang besar pada tatanan nilai tradisional dan keadaan sosial budaya masyarakat pendukungnya, bahkan mengubah sifat dasar moralitas serta kepribadian terutama bagi generasi muda (Wabaa dkk, 2014). Misalnya, banyak orang yang merasa ketinggalan zaman kalau tidak berdandan dan berperilaku seperti bintang film asing, kenakalan remaja, lunturnya adab sopan santun kepada orang tua dan guru, penggunaan narkoba dan minuman keras dsb. Saat ini telah terjadi dekadensi moral pada kalangan tertentu, khususnya kaum remaja, sehingga perilakunya menyimpang dari nilai-nilai agama dan budaya ketimuran kita. Akibat globalisasi menganut kebebasan dan keterbukaan sehingga mereka bertindak sesuka hati mereka (Ngafifi, 2014)

\section{Simbolisasi Makna Kegigihan Mengejar Cita- cita}

Dalam "Keong Emas" tokoh Dewi Galuh iri hati terhadap kecantikan Candra Kirana. Kemudian ia meminta Nenek Sihir agar menyihir Candra Kirana agar menjadi wanita yang berwajah jelek dan menjijikkan. Tujuannya adalah agar Chandra Kirana dibuang dan Inu Kertapati pun tidak mencintainya. Chandra kirana mengami penderitaan yang panjang. Ia dibuang disungai sehingga berubah menjadi Keong Emas. Beruntung kemudian dtemukan seorang Nenek dan mau memelilharanya di tempayan depan rumah.

.....Candra Kirana menceritakan perbuatan Dewi Galuh pada Baginda Kertamarta. Baginda minta maaf kepada Candra Kirana dan sebaliknya. Dewi Galuh lalu mendapat hukuman yang setimpal. Karena Dewi Galuh merasa takut, maka dia melarikan diri ke hutan. Akhirnya pernikahan Candra kirana dan Raden Inu Kertapati pun berlangsung, dan pesta tersebut sangat meriah. Akhirnya mereka hidup bahagia.

(https://histori.id/legenda-keong-mas/) 
Usaha Candra Kirana untuk menyelamatkan diri telah membawa hasil. Orang yang baik dan jujur mendapat pertolongan dari orang lain. Kegigihan Candra Kirana dalam berjuang untuk bertahan hidup dari sungai, kemudian di tempayan Nenek (penanda) bermakna bahwa ia sangat gigih dalam memperjuangakan cita-cita (petanda).

Dalam "Timun Emas" tokoh Timun Emas menghaapi ujian yang berat, sebab ia akan dimangsa raksasa. Kemudian ia mencari jalan untuk menyelamatkan diri. Beruntung ia dapat bertemu dengan seorang Kakek Sakti yang memberikan berbagai jurus untuk melawan Raksasa. Jurus tersebut berupa melempar benih mentimun, duri, garam dan terasi ke hadapan Raksasa. Saat benih mentimun dlempar kemudian berubah menjadi tanaman yang lebat, duri berubah menjadi hutan, garam berubah menjadi lautan, dan terasi berubah menjadi lumpur.

Tubuh raksasa yang besar tidak mampu melawan hisapan lumpur karena kelelahan. Ia pun tewas terhisap lumpur. Maka, tamatlah riwayat raksasa jahat itu. Setelah bebas dari raksasa jahat itu. Kehidupan Timun Mas dan Mbok Yem membaik.

Timun Mas bertemu dengan seorang pangeran dari negeri seberang. Pangeran itu jatuh cinta kepadanya. Merekapun menikah. Timun Mas dan Mbok Yem oleh pangeran itu ke istananya. Mereka hidup bahagia selamanya. (https://dongengceritarakyat.com/cerita-legendatimun-mas-dongeng/diboyong)

Sikap Timun Emas yang cukup berani menghadapi amarah Raksasa (penanda) dapat dimaknai sebagai pejuang yang gigih dalam menggapai impiannya (petanda). Tanpa perjuangan yang berdarah-darah dan tak mengenal lelah, kecil kemungkinan ia dapat memenangkan pertarungan itu. Akhirnya malah Tumun Emas dipinang seorang Pangeran dari seberang.

\section{Makna Konotatif}

Keberanian Timun Emas dalam memperjungkan cita-citanya (penanda) secara konotatif mengacu kepada banyak figure di tanah yang mendapat sukses di berbagai bidang lantaran usahanya yang keras tidak mengenal lelah (petanda). Sebagai contoh, penguasaha nasional Chairul Tanjung yang memiliki kekayaan di atas Rp 50 trilyun bukan anak orang kaya. Sejak kecil ia hidup susah tinggal di rumah petak yang dihuni 8 orang. Ia sekolah sambil bekerja di foto copy, berjualan kaos dsb. Kegigihannya dalam meperjuangnkan cita-cita dapat membawanya kuliah di Universitas Indonesia dengan biaya sendiri. Kini ia menjadi salah sati konglomerat terpandang dengan bisnis di bidang media, industry hiburan, mall dll. Banyak konglomerat Indonesia yang memulai usahanya dari bawah seperti Ahamd Zaky (Bukalapak), Roby Hidayat (Sido Muncul) dsb. Para konglomerat tersebut menjadi menjadi besar bukan karena memiliki modal besar sebelumnya, mamun semua itu dirintis dari bawah. Kegigihan, kerja keras, keuletan yang tanpa batas menyebabkan mereka sukses sesuai dengan impiannya. Inilah salah satu makna konotatif dari kegigihan Timun Emas dalam memperjuangkan bisa lepas dari ancaman.

\section{Simbolisasi Makna Nilai-nilai Kebaikan}

Mbok Yem ('Timun Emas') menolak Timun Emas akan dimangsa Raksasa, sebab ia sangat menyayangi Timun Emas. Kegigihan Mbok Yem mempertahankan Timun Emas dari Raksasa (penanda) menunjukkan ia perempuan yang baik dan berhati mulia (petanda). Dalam 'Keong Emas"' Tokoh Inu Kertapati dan Candra Kirana tidak menunjukkan amarahnya kepada Dewi Galuh dan Permaisuri sekalipun mereka telah memfitnah Candra Kirana (penanda). Hal ini membuktikan bahwa Kertapati dan Candra Kirana orang yang berjiwa besar dan baik hati (petanda). Tokoh Para Dewa (Narada dkk) ("Dumadining Gunung Merapi' ') memindah Gunung Dwipa ke Tanah Jawa demi keselamatan manusia (penanda). Tindakan Para Dewa menunjukkan bahwa mereka baik hati, selalu berbuat untuk kepentingan kemanusiaan (petanda). Tokoh Fatimah dalam 'Penyesalan Anak Durhaka' tidak pernah membalas saat Putri selalu menghina dan melecehkannya (penanda). Ia selalu bersabar dan berdoa agar anaknya berubah menjadi anak yang baik (petanda).

Mbok Yem, Dewa Narada dkk, Inu Kertapati, Chandra Kirana, dan Fatimah sebagai tokoh-tokoh yang baik hati, bijaksana, dan sabar (penanda) secara konotatif mengacu kepada tokoh-tokoh masyarakat seperti pejabat negara, agamawan, politisi dan wakil rakyat, budayawan,pendidik, akademisi dsb yang amanah. Tentu saja peneliti tidak perlu menyebut nama dari masing-masing tokoh tersebut. Di negeri ini masih ada politisi, wakil rakyat, dan pejabat negara yang baik. Mereka masih aspiratif memperjuangkan hak-hak masyarakat daripada kelompoknya. Budayawan yang senantiasa berpikir tanpa lelah untuk kemajuan seni budaya bangsanya masih banyak. Akademisi yang aktif bergelut dengan tulus mengembangkan iptek demi kemajuan pendidikan dan iptek cukup banyak. Para guru berprestasi yang mendidik murid dengan penuh idealisme banyak tersebar di pelosok negeri. Para tokoh agama yang membimbing umat dengan penuh 
persuasive dan berintegritas tersebar di seantero negeri. Para tokoh bangsa yang amanah, berintegritas, dan berakhlak mulya tersebut merupakan makna konotatif (petanda) dari nilainilai positif yang terkandung empat drama anak karya Nanang Arizona.

\section{Makna Kontekstual}

Kehidupan masyarakat Indonesia yang selama ini terkenal cukup menjunjung tinggi nilai-nilai agama, dan kental dengan kearifan nilai-nilai tradisional kini seolah-seolah seperti mendapat "goncangan hebat" dengan meluasnya siaran televisi, penggunaan internet, gadget dsb. Bukan rahasia lagi bahwa ada sebagai kelompok yang justru larut dalam sistem nilai yang baru yang datang dari Barat itu. Terbukti semakin merebaknya kemerosotan moral di kalangan generasi muda yang antara lain ditandai dengan penggunaan narkoba, minuman keras, tindak kekerasan pergaulan bebas, gaya hidup ala Barat, dsb. Kemampuan masyarakat dalam menyaring informasi yang berasal dari luar masih emah. Akibatnya, tanpa disadari sebagian masyarakat telah terjebak dengan gaya hidup dan pandangan hidup Barat. Tantangan masa depan kehidupan masyarakat era globalisasi ini cukup kompleks, sebab diwarnai oleh perubahan masyarakat yang cukup cepat dengan diikuti adanya pergeseran sistem nilai yang juga cepat (Sudarminta dalam Drost dkk, 2000: 78).

Dalam kondisi seperti inilah, diperlukan ketahanan mental dan spiritual masyarakat dalam menghadapi arus informasi yang semakin mengglobal ini. Hal ini berdasarkan pertimbangan bahwa kemampuan setiap orang dalam menyerap informasi berbedabeda. Latar belakang pendidikan, agama, dan pengetahuan intelektual setiap individu ikut menentukan kualitas penyerapan informasi. Salah satu jalan untuk menyelamatkan kehidupan masyarakat agar tidak terjerumus pada sistem nilai baru yang tidak seutuhnya sesuai adalah dengan meningkatkan ketahanan mental dan spiritual melalui sosialisasi nilai-nilai postif dari karya seni, termasuk drama-drama anak, dan dongengedongeng Nusantara.

Apabila karya seni yang berkualitas dapat dimasukkan dalam program-program pendidikan bukan tidak mungkin dapat membantu menumbuhkembangkan peserta didik generasi masa kini menjadi lebih relijius, memiliki kedalaman perasaan, cerdas dalam berpikir, menigkatkan kepekaan sosial, dan menyukai budaya bangsa sendiri maupun bangsa lain. Nilai budaya lokal untuk reorientasi pendidikan keindonesiaan dalam rangka pengembangan pendidikan yang berbasis budaya Indonesia dirasa perlu untuk mewujudkan cita-cita pendidikan Indonesia yaitu masyarakat yang demokratis, cerdas secara intelek, tual, emosional, etika dan estetika sehingga benar-benar menjadi manusia terdidik yang beradab (Susitiawati, 2018). Dimasukkannya budaya lokal semacam drama anak-anak berbasis dongeng Nusantara dalam khazanah pendidikan secara tidak langsung dapat melestarikan budaya local sekaligus ikut mengembangkan budaya nasional.

Kandungan nilai-nilai edukatif dalam drama anakanak dapat menjadi media pendidikan budi pekerti atau pendidikan karkater bagi generasi masa kini. Tujuan utama pendidikan budi pekerti adalah membentuk anak didik menjadi manusia seutuhnya yang berbudi pekerti luhur dapat melaksanakan tugas-tugas hidupnya dengan selaras, serasi, seimbang lahir batin, jasmani maupun pun rohani, material spiritual, individual sosial dan dunia akhirat (Depdikbud dalam Wangsa dkk, 2019). Dengan cara demikian diharapkan generasi masa kini dapat mengenal warisan budaya bangsanya, sekaligus mendapatkan pencerahan lewat nilai-nilai edukatif dalam kaarya tersebut.

\section{SIMPULAN}

Berdasarkan kajian di atas dapat disimpulkan bahwa: Pertama, berbagai dongeng Nusantara yang jumlahya cukup banyak dapat digubah maupun diadaptasi sesuai selera masuarakat masa kini, misalnya dalam genre seni drama, sekenio film dsb; Kedua, setelah dikaji secara semiotika keempat drama anak-anak hasil gubahan Nanang Arizona mengandung makna-makna denotative yang terkait dengan dengan kesrakahan dan egoisme, ketidakadilan, pegergeseran sistem nilai masyarakat, dan kegigihan dalam mengejar cita-cita, dan nilai-nilai kebaikan; Ketiga, kelima makna demotatif tersebut memiliki makna konotatif terkait dengan kondisi sosial historis masyarakat Indonesia sekarang. Keempat, makna-makna dalam keempat drama cukup relevan untuk pendidikan moral atau pendidikan budi pekerti generasi sekarang, sehingga sudah layaknya dongeng-dongeng Nusantara beserta turunan hasil gubahan dari karyakarya tersebut diperkenalkan kepada generasi sekarang.

\section{DAFTAR PUSTAKA}
Anonim.
''Timun
Emas"
(https://dongengceritarakyat.com/cerita-legenda-
timun-mas-dongeng/). 
keong-mas/)

''Keong Mas', (https://histori.id/legenda. dan 'Batu Menangis", (https://dongengceritarakyat.com/cerita-rakyatlegenda-batu-menangis/ )

Al-Shraideh, Mona dan Ahmad El-Sharif2. (2019). A Semiotic Perspective on the Denotation and Connotation of Colours in the Quran. International Journal of Applied Linguistics \& English Literature, (8) 1 , 18-33. http://dx.doi.org/10.7575/aiac.ijalel.v.8n.1p.18

Amrunsyah. (2017). Tajam ke Bawah Tumpul ke Atas (Tinjauan Implemetasi Hukum Pidana di Indonesia). M.H LEGALITE $\bar{E}$ : Jurnal Perundang Undangan dan Hukum Pidana Islam, (II)1, 50-73. https://journal.iainlangsa.ac.id/index.php/legalite/ar ticle/view/294

Arizona, Nanang. (2014). 'Putri Si Anak Durhaka', Yogyakarta: Naskah Tidak Diterbitkan.

. (2016). "Malapetaka Sang Raksasa',. Yogyakarta: Naskah Tidak Diterbitkan.

(2017). 'Candra Kirana', Yogyakarta: Naskah Tidak Diterbitkan.

(2018). "'Asal-usul Gunung Merapi'. Yogyakarta: Naskah Tidak Diterbit

Elain Aston and George Savona (1999). Theatre As Sign-System A Semiotics of Text and Performance. New York: Routledge

A Semiotics of Text and Performance, Routledge, New York, 1999, pp. 10.

Berger, Arthur Asa. (2014). Symposium: Signs, Symbols, and Semiotics. Semiotics and Sosiety, 52, 22-26. https://doi.org/10.1007/s12115-013-9731-4

Binder, Werner. (2018). Review Essay he semiotics of social life. American Journal of Cultural Sociology, 6, 401-416. https://doi.org/10.1057/s41290-017-0038-6

Choiriyah, C. (2020). Penerapan Living Values Education Program dalam Pembentukan Karakter Anak Usia 4-6 Tahun di TK Islam Al Fikri Bekasi. JPP PAUD FKIP Untirta, (7)1, 11-22. http://jurnal.untirta.ac.id/index.php/jpppaud/index,

Elam, Keir. (1991). The Semiotic Theatre and Drama. Londong: Rout-ledge.
Ernawati, Kristina. (2017). ''Dumadine Gunung Merapi'. R Bambang Nursinggih (ed.), Yogyakarta: CV Arindo Nusa Media.

Fitroh, Siti Fadjryana dan Evi Dwi Novita Sari. (2015). Dongeng sebagai Media Penanaman Karakter Pada Anak Usia Dini. Jurnal PG-PAUD Trunojoyo, (2)2, 76-149. https://doi.org/10.21107/pgpaudtrunojoyo.v2i2.260 $\underline{6}$

Ka'bah, Rifyal. (2007). Korupsi di Indonesia. Jurnal Hukum dan Pembangunan, (37)1, 77-89. doi: http://dx.doi.org/10.21143/jhp.vol37.no1.144

Mu'allifin, Darin Arif, M. (2015). Problema dan Pemberantasan Korupsi di Indonesia. AHKAM, (3) $2,311-325$.

Mitchell Jr, Donald, Elizabeth T. Byron, Jeffrey B. Cross , O.J. Oleka, Stephanie N. Van Eps Phyllis L. Clark, Natalie S. Sajko (2020). Going in Thinking Process, Coming Out Transformed: Reflflections and Recommendations From a Qualitative Research Course. Social Sciences \& Humanities Open (2) 0003.

https://doi.org/10.1016/j.ssaho.2020.100031

Muhdar, M. (2016). Keadilan Ekonomi di Tinjauan Kesempatan Kerja dan Pengangguran. Al-Buhuts, 12(1), 102-136. https://journal.iaingorontalo.ac.id/index.php/ab/arti cle/view/61

Ngafifi Muhamad. (2014) Kemajuan Teknologi dan Pola Hidup Manusia dalam Perspektif Sosial Budaya. Jurnal Pembangunan Pendidikan: Fondasi dan Aplikasi, (2)1, 33-47.

Noth, Winfried. (1990). Handbook of Semiotics. Indiana Polis: Indiana University Press.

Parmadie, B., Kumbara, A. N. A., Wirawan, A. B., \& Sugiartha, I. G. A. (2018). Pengaruh Globalisasi Dan Hegemoni Pada Transformasi Musik Dol Di Kota Bengkulu. Mudra Jurnal Seni Budaya, 33(1), 67-75. https://doi.org/10.31091/mudra.v33i1.240

Pradopo, Rachmat Djoko.(2000). "Kajian Semiotika". Yogyakarta: Makalah Seminar Peresmian Pembukaan Pusat Studi Sastra UGM Yogyakarta.

(2013) Pengkajian Puisi. Yogyakarta: Gadjah Mada University Press. 
Riffaterre, Michael. (1982). Semiotic of Poetry. Bloomington and London: Indiana University Press.

Sahid, N., Susantina, S., Purwanta, P., \& Septiawan, N. (2017). Penciptaan Drama Radio Ratu Adil: Prahara Tegalrejo Sebagai Media Pendidikan Karakter. Mudra Jurnal Seni Budaya, 32(1). https://doi.org/10.31091/mudra.v32i1.85

Sahid, Nur. (2019). Semiotika untuk Teater, Tari, Film, dan Wayang Purwa. Yogyakarta: Pustaka Pelajar.

Setiawan, H., Rakhmawati, A., \& Anindyarini, A. (2020). Pertunjukkan Ketoprak Lakon Pedhut Jatisrana Sebagai Media Pendidikan Karakter. Mudra Jurnal Seni Budaya, 35(3), 331-336. https://doi.org/10.31091/mudra.v35i3.1008

Sudarminto, J. (2000). "Tantangan dan Permasalahan Pendidikan di Indonesia Memasuki Milenium Ketiga", dimuat dalam J. Drost dkk. (Eds.),Transformasi Pendidikan Memasuki Milenium Ketiga. Yogyakarta.Universitas Sanata Dharma.

Sugiono. (2015). Metode Penelitian Pendidikan: Pendekatan Kuantitatif, Kualitatif dan $R \& D$. Bandung: Alfabeta.

Sunaryo, E., Sahid, N., \& Nizam, A. (2017). Ragam Hias Beberapa Masjid di Jawa: Kajian Sejarah Kebudayaan dan Semiotika. Mudra Jurnal Seni Budaya, 31(2). https://doi.org/10.31091/mudra.v31i2.27

Sustiawati, N. L., Suryatini, N. K., \& Mayun Artati, A. A. A. (2018). Pengembangan Desain Pembelajaran Seni Tari Di Sekolah Dasar Berbasis Localgenius Knowledge Berpendekatan Integrated Learning. Mudra Jurnal Seni Budaya, 33(1), 128143. https://doi.org/10.31091/mudra.v33i1.322

Teeuw, A. (1984). Sastra dan Ilmu Sastra. Jakarta: Pustaka Jaya.

Wabaa, Martha dkk. (2014). Pengaruh Globalisasi Informasi terhadap Kehidupan Sosial Bbudaya Generasi Muda (suatu Studi di SMA Negeri 1 Beo), Kabupaten Kepulauan Talaud. Jurnal Administrasi Publik, (4)5, 52-61. https://ejournal.unsrat.ac.id/index.php/JAP/article/v iew/5869

Wangsa, B. S., Sulistyo, E. T., \& Suyanto, S. (2019). Makna Budi Pekerti Remaja pada Serat Wulangreh Karya Pakubuwono IV: Pupuh Macapat Durma.
Mudra Jurnal Seni Budaya, 34(3), 325-329. https://doi.org/10.31091/mudra.v34i3.681

Wellek, Rene dan Warren Austin, (1989). Teori Satera. Jakarta: Gramedia.

Wibowo, Iswanto Ary \& Akbar ,Ali. (2017). Figurative Language in the Room of My Life's Poem by Anne Sexton and Still I Rise's Poem by Maya Angelou. IJOLTL, (2)2, 117-130. https://doi.org/10.30957/ijoltl.v2i2.275

Yoga, Saman. (2018). Perubahan Sosial Budaya Masyarakat Indonesia dan Perkembangan Teknologi Komunikasi. Jurnal Al-Bayan, (24)1, 2946.

DOI: http://dx.doi.org/10.22373/albayan.v24i1.3175 